\title{
Image of the month: Target the bugs: Strongyloides stercoralis hyperinfection
}

\author{
Authors: Akira Hokama ${ }^{A}$ and Kazuto Kishimoto ${ }^{B}$
}

\begin{abstract}
A 74-year-old woman carrying the human T-lymphotropic virus type-1 (HTLV-1) presented with abdominal pain and vomiting. Computed tomography and microscopic analysis of the gastroduodenal drainage fluid made a diagnosis of paralytic ileus due to Strongyloides stercoralis hyperinfection with underlying HTLV-1 infection. Strongyloidiasis should be included in the differential diagnosis for paralytic ileus in patients who have lived in or migrated from the endemic regions.
\end{abstract}

KEYWORDS: Strongyloides stercoralis, hyperinfection, human T-lymphotropic virus type 1 , ileus, computed tomography

DOI: $10.7861 /$ clinmed.2020-1000

\section{Case presentation}

A 74-year-old woman presented with abdominal pain, diarrhoea and vomiting for 2 weeks. She had a history of bronchial asthma and her medication included budesonide inhalation solution. Physical examination revealed stable vital signs and leg oedema. Her abdomen was soft, distended and nontender with decreased bowel sounds. Laboratory examination showed white blood cells of $8.1 \times 10^{9} / \mathrm{L}$, C-reactive protein of $2.2 \mathrm{mg} / \mathrm{L}$ (normal range $<1.4$ ), and albumin of $29 \mathrm{~g} / \mathrm{L}$ (normal range $41-51$ ). Antibodies to human T-lymphotropic virus type-1 (HTLV-1) were positive. Abdominal contrast-enhanced computed tomography showed mural thickening with 'target sign' enhancement of the small intestine (Fig 1). On admission, nasogastric tube drainage was performed, and the microscopic analysis of the gastroduodenal drainage fluid revealed Strongyloides stercoralis larvae (Fig 2). A diagnosis of paralytic ileus due to $S$ stercoralis hyperinfection with underlying HTLV-1 infection was made. Treatment of oral ivermectin at $200 \mu \mathrm{g} / \mathrm{kg}$ for 7 days was initiated, resulting in successful eradication and prompt clinical improvement.

\section{Discussion}

$S$ stercoralis can persist in the intestine for decades and approximately 400 million people are infected worldwide. Immunosuppressive conditions (including ageing, immunosuppressive medication and

Authors: ${ }^{A}$ associate professor, University of the Ryukyus, Nishihara, Japan; ${ }^{B}$ Consultant gastroenterologist, University of the Ryukyus, Nishihara, Japan

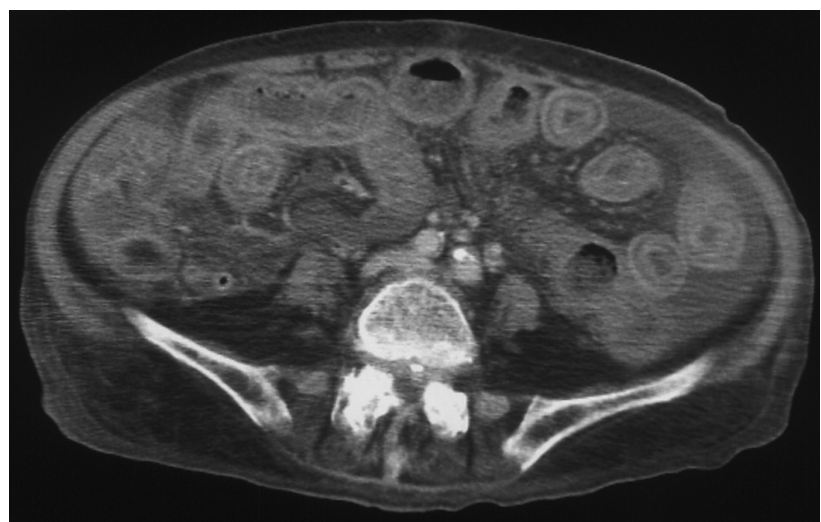

Fig 1. Enhanced computed tomography showing mural thickening with 'target sign' enhancement of the small intestine and ascites.

co-infection with HTLV-1) can cause life-threatening hyperinfection syndrome, characterised by paralytic ileus and Gram-negative bacteraemia. ${ }^{2,3}$ Co-infection of $S$ stercoralis and HTLV-1 affects each

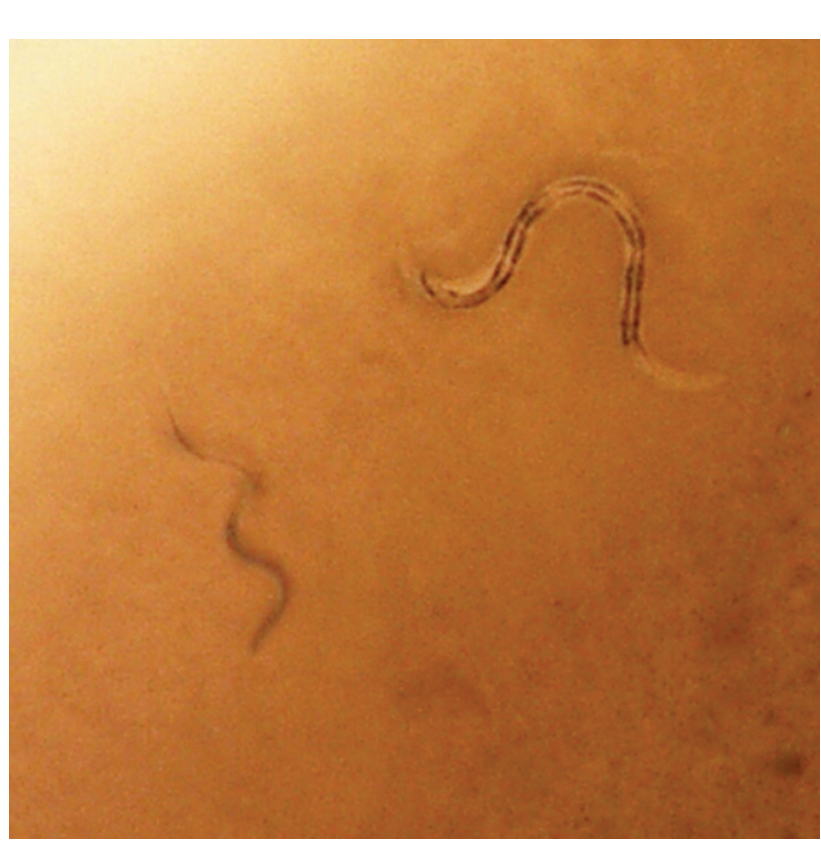

Fig 2. Microscopic imaging of the gastroduodenal drainage fluid revealing Strongyloides stercoralis Iarvae. 
other through altering immunity. ${ }^{3}$ Strongyloidiasis should be included in the differential diagnosis for paralytic ileus in patients who have lived in or migrated from endemic regions, such as Asia, Africa and South America.

\section{References}

1 Fleitas PE, Travacio M, Martí-Soler H et al. The Strongyloides stercoralishookworms association as a path to the estimation of the global burden of strongyloidiasis: A systematic review. PLoS Negl Trop Dis 2020;14:e0008184.
2 Kishimoto K, Hokama A, Hirata T et al. Endoscopic and histopathological study on the duodenum of Strongyloides stercoralis hyperinfection. World J Gastroenterol 2008;14:1768-73.

3 Hirata T, Uchima N, Kishimoto $\mathrm{K}$ et al. Impairment of host immune response against Strongyloides stercoralis by human T cell lymphotropic virus type 1 infection. Am J Trop Med Hyg 2006;74:246-9.

Address for correspondence: Dr Akira Hokama, Department of Endoscopy, Graduate School of Medicine, University of the Ryukyus, 207 Uehara, Nishihara, Okinawa 903-0215, Japan. Email: hokama-a@med.u-ryukyu.ac.jp 